PREPARED FOR THE U.S. DEPARTMENT OF ENERGY, UNDER CONTRACT DE-AC02-76CH03073

PPPL-3815

PPPL-3815

UC-70

Beta-limiting MHD Instabilities
in Improved-performance NSTX Spherical Torus Plasmas

by

J.E. Menard, M.G. Bell, R.E. Bell, E.D. Fredrickson, D.A. Gates, S.M. Kaye,

B.P. LeBlanc, R. Maingi, D. Mueller, S.A. Sabbagh, D. Stutman,

C.E. Bush, D.W. Johnson, R. Kaita, H.W. Kugel, R.J. Maqueda,

F. Paoletti, S.F. Paul, M. Ono, Y.-K.M. Peng, C.H. Skinner,

E.J. Synakowski, and the NSTX Research Team

May 2003

NM|

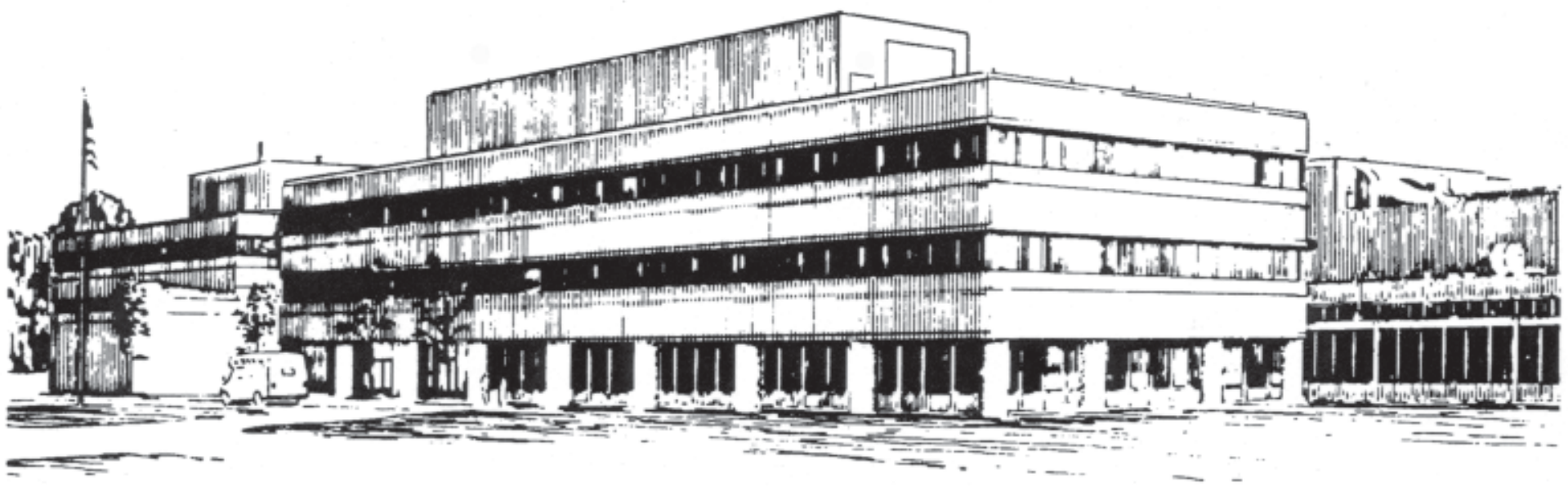

PRINCETON PLASMA PHYSICS LABORATORY PRINCETON UNIVERSITY, PRINCETON, NEW JERSEY 


\section{PPPL Reports Disclaimer}

This report was prepared as an account of work sponsored by an agency of the United States Government. Neither the United States Government nor any agency thereof, nor any of their employees, makes any warranty, express or implied, or assumes any legal liability or responsibility for the accuracy, completeness, or usefulness of any information, apparatus, product, or process disclosed, or represents that its use would not infringe privately owned rights. Reference herein to any specific commercial product, process, or service by trade name, trademark, manufacturer, or otherwise, does not necessarily constitute or imply its endorsement, recommendation, or favoring by the United States Government or any agency thereof. The views and opinions of authors expressed herein do not necessarily state or reflect those of the United States Government or any agency thereof.

\section{Availability}

This report is posted on the U.S. Department of Energy's Princeton Plasma Physics Laboratory Publications and Reports web site in Fiscal Year 2003. The home page for PPPL Reports and Publications is: http://www.pppl.gov/pub_report/

DOE and DOE Contractors can obtain copies of this report from:

U.S. Department of Energy

Office of Scientific and Technical Information

DOE Technical Information Services (DTIS)

P.O. Box 62

Oak Ridge, TN 37831

Telephone: (865) 576-8401

Fax: (865) 576-5728

Email: reports@adonis.osti.gov

This report is available to the general public from:

National Technical Information Service

U.S. Department of Commerce

5285 Port Royal Road

Springfield, VA 22161

Telephone: $1-800-553-6847$ or

(703) $605-6000$

Fax: (703) 321-8547

Internet: http://www.ntis.gov/ordering.htm 


\title{
Beta-limiting MHD instabilities in improved-performance NSTX spherical torus plasmas
}

\author{
J.E. Menard ${ }^{1}$, M.G. Bell ${ }^{1}$, R.E. Bell ${ }^{1}$, E.D. Fredrickson ${ }^{1}$, D.A. Gates ${ }^{1}$, \\ S.M. Kaye ${ }^{1}$, B.P. LeBlanc ${ }^{1}$, R. Maingi ${ }^{2}$, D. Mueller ${ }^{1}$, S.A. Sabbagh ${ }^{3}$, \\ D. Stutman ${ }^{4}$, C.E. Bush ${ }^{2}$, D.W. Johnson ${ }^{1}$, R. Kaita ${ }^{1}$, H.W. Kugel ${ }^{1}$, \\ R.J. Maqueda ${ }^{5}$, F. Paoletti ${ }^{3}$, S.F Paul ${ }^{1}$, M. Ono ${ }^{1}$, Y.-K.M. Peng ${ }^{2}$, C.H. Skinner ${ }^{1}$, \\ E.J. Synakowski ${ }^{1}$, and the NSTX Research Team. \\ ${ }^{1}$ Princeton Plasma Physics Laboratory, Princeton, NJ, USA \\ ${ }^{2}$ Oak Ridge National Laboratory, Oak Ridge, TN, USA \\ ${ }^{3}$ Columbia University, New York, NY, USA \\ ${ }^{4}$ Johns Hopkins University, Baltimore, MD, USA \\ ${ }^{5}$ Los Alamos National Laboratory, Los Alamos, NM, USA
}

\begin{abstract}
Global magnetohydrodynamic stability limits in the National Spherical Torus Experiment (NSTX) have increased significantly recently due to a combination of device and operational improvements. First, more routine $\mathrm{H}$-mode operation with broadened pressure profiles allows access to higher normalized beta and lower internal inductance. Second, the correction of a poloidal field coil induced error-field has largely eliminated locked tearing modes during normal operation and increased the maximum achievable beta. As a result of these improvements, peak beta values have reached (not simultaneously) $\beta_{t}=35 \%, \beta_{N}=6.4,\left\langle\beta_{N}\right\rangle=4.5, \beta_{N} / l_{i}=10$, and $\beta_{P}=1.4$. High $\beta_{P}$ operation with reduced tearing activity has allowed a doubling of discharge pulse-length to just over 1 second with sustained periods of $\beta_{N} \approx 6$ above the ideal no-wall limit and near the with-wall limit. Details of the $\beta$ limit scalings and $\beta$-limiting instabilities in various operating regimes are described.
\end{abstract}

\section{Introduction}

The spherical torus [1] (ST) concept is being actively researched in order to assess the viability of the concept as an energy producing device and to improve the understanding of toroidal magnetic confinement concepts in general. For the ST to efficiently produce energy in steady-state, high $\beta$ must be combined with high bootstrap fraction $[2,3]$. Recent experiments on the National Spherical Torus Experiment (NSTX) $[4,5]$ have made significant progress in reaching high toroidal beta $\beta_{T} \leq 35 \%$ and in achieving long discharge duration by operating at high poloidal beta $\beta_{P} \leq 1.4$ in separate operating regimes. Typical parameters for present NSTX plasmas are: major radius $R_{0}=0.85-0.9 \mathrm{~m}$, aspect ratio $\mathrm{A}=R_{0} / a>1.3-1.5$, elongation $\kappa<2.4$, triangularity $\delta<0.8$, vacuum toroidal field $B_{T 0}=0.3-0.6$ Tesla at $R_{0}$, plasma current $I_{p}<1.5 \mathrm{MA}$, and plasma pulse length up to 1 second.

Several device and operational improvements have enhanced the overall stability of NSTX plasmas relative to results obtained as recently as one year ago [6]. Boronization [7], high temperature $\left(350^{\circ} \mathrm{C}\right)$ bake-out of the plasma facing components, and other conditioning techniques have reduced impurity levels [8] and allow more reliable access to the H-mode [9]. The resulting broader pressure profile and reduced internal inductance resulting from increased off-axis bootstrap current has allowed operation with significantly higher normalized beta $\beta_{N} \approx 6$. A poloidal field coil induced error field was also discovered and corrected. This correction largely eliminated locked tearing modes during normal operation and effectively raised the $\beta$ limit by facilitating routine operation above the no-wall limit in regimes with sufficiently high plasma rotation, elevated $q(0)$, and broad pressure profiles. Finally, optimizations of boundary shape and discharge evolution have resulted in discharges with extended periods free of both edge localized modes (ELMs) and sawtooth activity. In such regimes, high $\beta_{P}$ has been combined with high $\beta_{N}$ to achieve $800 \mathrm{kA}$ discharges with sustained operation above the $\mathrm{n}=1$ ideal no-wall stability limit and near the withwall limit for several energy confinement times and many resistive wall times. Tearing modes are found to limit the achievable $\beta$ at high $\beta_{T}$ and to degrade 
but not severely limit confinement in regimes with high $\beta_{P}$ at higher toroidal field.

The remainder of this article is outlined as follows. First, Section 2. discusses the impact of error field reduction on vacuum island widths and mode locking in NSTX. Section 3. reviews global stability improvements as a function of normalized current, pressure profile peaking, internal inductance, and discharge shape. Section 4 . discusses the betalimiting MHD modes typically observed in high $\beta_{T}$ and high $\beta_{P}$ discharges. Section 5. describes initial work investigating the impact of rapid rotation and strong rotational shear on equilibrium and stability. Finally, these results are summarized in Section 6 .

\section{Error fields and locked modes}

Resonant error fields resulting from loss of axisymmetry due to coil misalignments and other construction imperfections are well known to potentially lead to tokamak performance degradation [10-13]. This degradation typically occurs when the electromagnetic torque applied to resonant surfaces by the error field cannot be overcome by the intrinsic or externally driven torque of the plasma leading to error field penetration (locking) and loss of plasma rotation. This process appears to be particularly important near and above the ideal no-wall limit where error field amplification can lead to strong rotation damping and destabilization of the resistive wall mode (RWM) in advanced tokamak regimes [14].

In order to investigate locked mode and resistive wall mode physics in NSTX, a radial field detector array was been installed to measure $\mathrm{n}=1$ radial magnetic field perturbations. Six large-area $B_{R}$ sensors cover the full toroidal circumference of NSTX, and as seen in Figure 1, the sensors are mounted symmetrically about the mid-plane and very close to the PF5 primary vertical field (VF) coils. Additional $B_{Z}$ and $B_{\phi}$ sensors mounted on each $B_{R}$ coil are used for cancellation of stray vertical and toroidal field pickup due to sensor misalignment, and voltage signals from internal flux loops are used for cancellation of transient fields from structural eddy currents. These additional sensors allow the plasma-induced $\mathrm{n}=1$ radial field to be measured to sub-Gauss accuracy. Early in the commissioning and calibration of these detectors it became apparent that a large effective shift of the lower PF5 coil was generating predominantly $n=1$ error-field over much of the NSTX plasma volume and local error-field magnitudes as large as 50 Gauss near the outboard plasma bound-

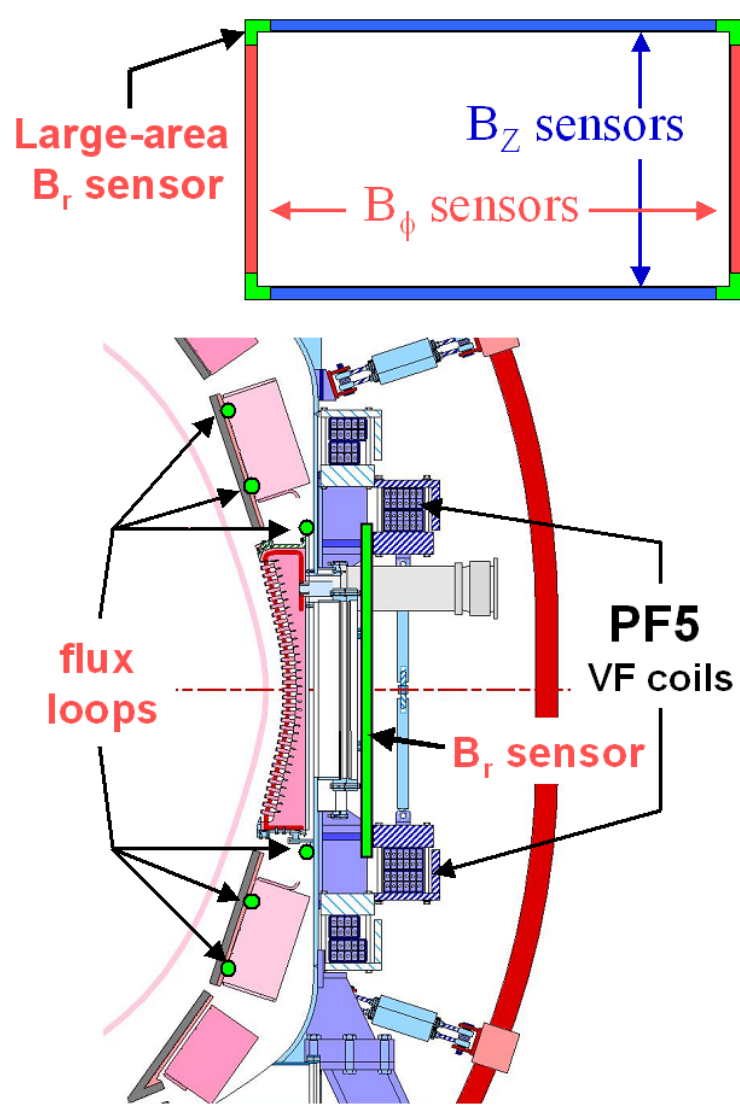

Figure 1. NSTX external $B_{R}, B_{Z}$, and $B_{\phi}$ sensors and internal flux loops used for the detection of error fields, locked modes, and resistive wall modes.

ary. For reference, the equilibrium field magnitude at the same location is typically 3-5 kGauss.

Detailed spatial measurements of the coil shape confirmed the magnetic measurements, and the coil was subsequently shifted and re-shaped to minimize the $n=1$ error field component. This reduction led immediately to improved performance - most noticeably in the locking behavior of ohmic discharges and beam-heated $\mathrm{H}$-mode discharges. Figures 2a-c illustrate that prior to error field reduction (dashed curves) ohmic discharges routinely exhibited minor disruptions in plasma current and major disruptions in plasma density during the $I_{p}$ flat-top phase. These disruptions typically occurred once the $\mathrm{q}=2$ surface entered the plasma and grew to sufficiently large minor radius even when the line-average density was twice that shown in Figure 2b. Figure 2d shows the typical 15-30ms growth time of a 4 Gauss locked mode which led to disruption. In contrast, the solid curves in Figure 2 show that following error field reduction there is no locking behavior evident until the solenoid current limit is reached (near $\mathrm{t}=290 \mathrm{~ms}$ ) 

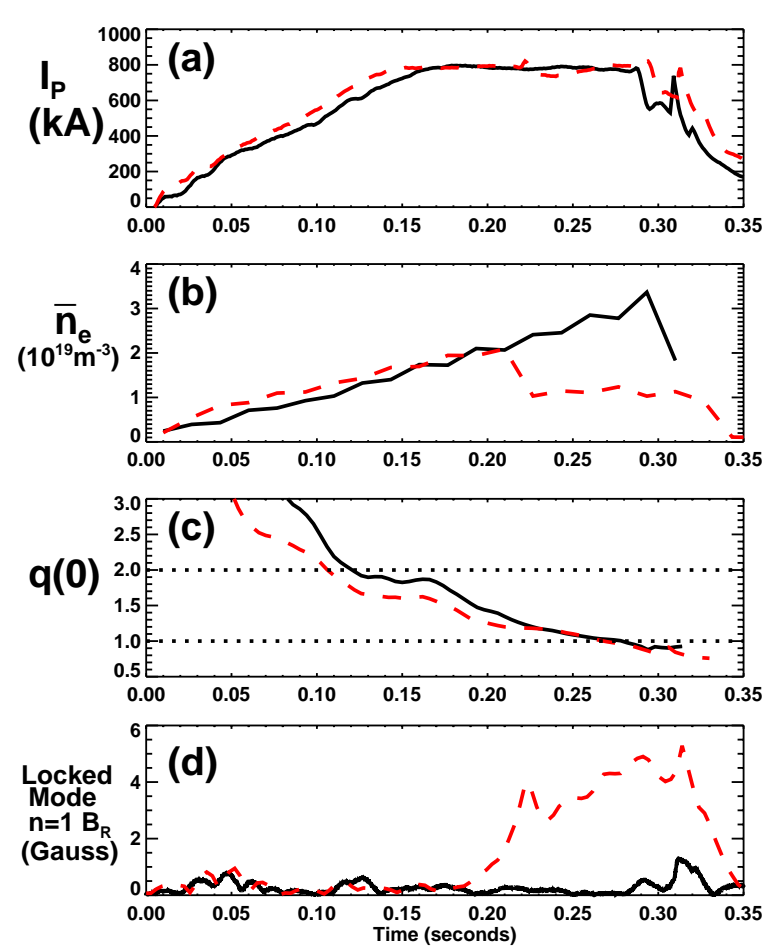

Figure 2. Comparison of $I_{p}=800 \mathrm{kA}, B_{T 0}=4.5 \mathrm{kG}$ ohmic discharges before (dashed) and after (solid) error field reduction on NSTX. (a) plasma current, (b) line-average density, (c) $q(0)$, and (d) $n=1$ locked mode amplitude measured outside the vessel.

and strong negative loop voltage is applied which disrupts the plasma. Subsequent density scans in the reduced error field configuration found locked modes could again be excited if the line-average density fell below $1.8 \times 10^{19} \mathrm{~m}^{-3}$ at $\mathrm{t}=250 \mathrm{~ms}$. This density is generally exceeded under normal operating conditions, and typically no longer limits performance.

Near-term locked mode research will focus on better understanding the role of toroidal field, density, safety factor, and rotation in the locking threshold. A first step in this research is the calculation of the perturbed vacuum field and flux from the measured coil shapes. In particular, the perturbed resonant poloidal flux can be used to calculate vacuum island widths [15] in general geometry [16] to begin to assess the locking drive. Figure 3 a plots the $n=1$ amplitude of the major radial component of the error field for the discharges from Figure 2 at $\mathrm{t}=200 \mathrm{~ms}$. As seen in the figure, the computed $n=1$ error field is largest on the outboard side and has been reduced by over an order of magnitude. Figure $3 \mathrm{~b}$ shows the corresponding $\mathrm{n}=1$ vacuum island widths in units of normalized poloidal flux calculated for various resonant poloidal mode numbers for the same discharges. As
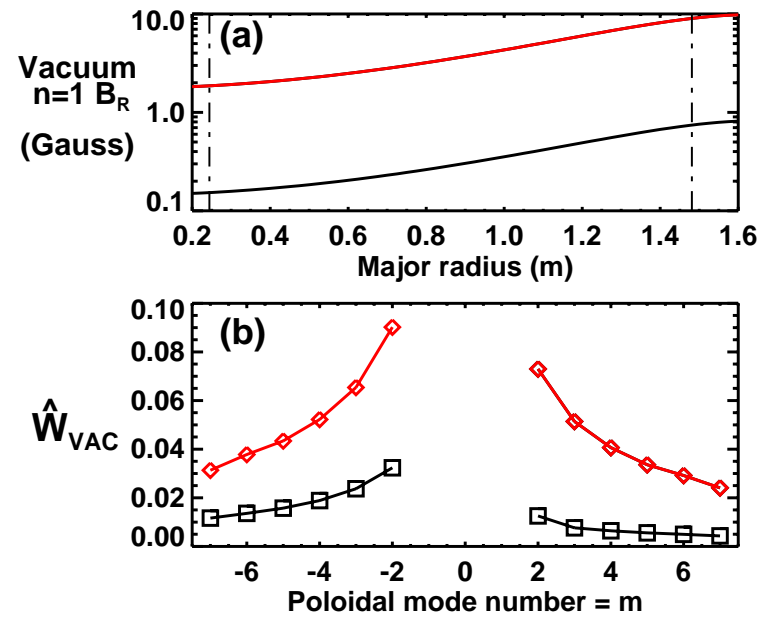

Figure 3. (a) n=1 amplitude of major-radial component of error field versus major radius at mid-plane and (b) $\mathrm{n}=1$ vacuum island widths in units of normalized poloidal flux before (upper curves) and after (lower curves) error field reduction for the discharges in Figure 2 at $\mathrm{t}=200 \mathrm{~ms}$. Vertical lines in (a) represent the plasma boundary.

expected, $|m / n|=2 / 1$ is the dominant helicity, and for the uncorrected error-field case (upper curves), vacuum island widths of up to $9 \%$ or $5 \mathrm{~cm}$ are calculated. This figure also shows that multiple resonant helicities may be active in the locking threshold for NSTX, although island widths of higher poloidal mode numbers drop by a factor of 3 as the plasma boundary is approached. In addition, for discharges with a $q=1$ surface present in the plasma, the $1 / 1$ vacuum island width is typically as large or larger than the $2 / 1$ width. This finding may explain the locking observed in some discharges that might otherwise have been expected to sawtooth with large inversion radius.

Normal NSTX operating parameters are such that positive poloidal mode numbers are resonant in Figure 3. Interestingly, this figure therefore implies that changing the sign of the resonant $m$ by changing the direction of either the toroidal field or plasma current with the present reduced error field configuration should have a measurable impact on the locking threshold. It should be noted that at the present time, only the shape of the PF5 coil set has been accurately measured, and other coils and current carrying structures may also be generating error fields. Internal toroidal arrays of radial and vertical field sensors placed above and below the midplane are presently being commissioned on NSTX to better diagnose the helical structure of error fields, locked modes, and resistive wall modes. 


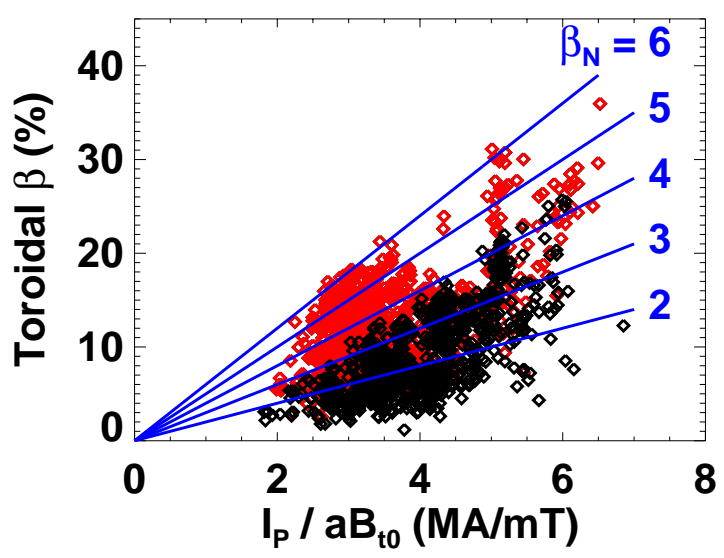

Figure 4. NSTX peak toroidal $\beta$ values plotted versus normalized current before (black) and after (red) machine improvements.

\section{Global Stability Improvements}

In addition to error field reduction, NSTX now routinely performs high-temperature bake-out of its graphite plasma facing components. This has led to comparatively easy access to the H-mode and significantly broader pressure profiles which are predicted to improve stability in various NSTX operating regimes $[17,18]$. These improvements are synergistic, as H-mode operation prior to error field reduction [19] was often degraded by the excitation of $2 / 1$ tearing modes which routinely slowed, locked to the large error field, and disrupted the plasma. Earlier experiments also often ran with plasmas limited on the centerstack to move the plasma away from the large outboard error field - essentially eliminating the possibility of H-mode access. In the figures that follow, the term "machine improvements" refers to the combination of error field reduction and high temperature bakeout. The relative importance of each of these improvements is discussed in Section 3.1..

Figure 4 shows the significant increase in $\beta$ due to the these improvements. As seen in the figure, $\beta_{N} \geq 6$ as determined by EFIT reconstructions $[20,21]$ using only external poloidal magnetic sensors has now been achieved for a wide range of normalized currents, and toroidal beta values $\beta_{T} \equiv 2 \mu_{0}\langle p\rangle / B_{T 0}^{2}$ as high as $35 \%$ have been achieved. The limits prior to these improvements are shown by the black symbols in the same figure. Recent theoretical work [22] has shown that the volume-averaged $\beta$ definitions $\langle\beta\rangle \equiv 2 \mu_{0}\langle p\rangle /\left\langle B^{2}\right\rangle$ and $\left\langle\beta_{N}\right\rangle \equiv\langle\beta\rangle(\%) a B_{T 0} / I_{p}(M A)$ are more suitable for comparing ideal stability limits across plasma aspect ratio. Plotted in these variables, Figure 5

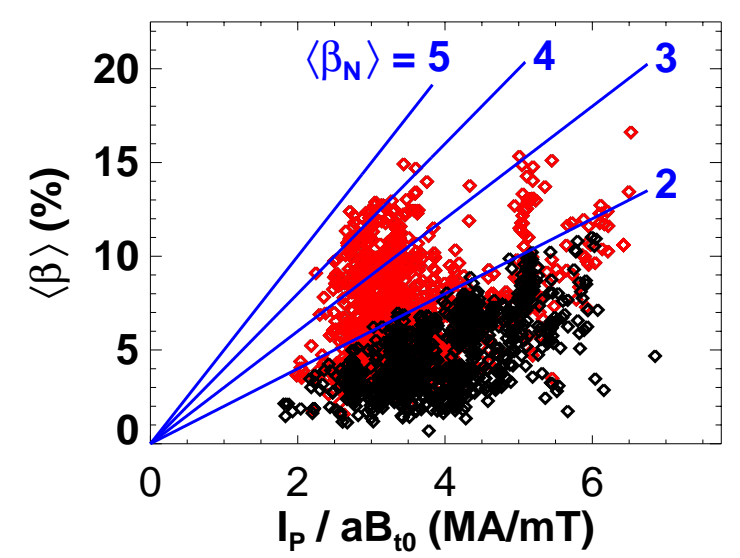

Figure 5. Peak volume-average $\beta$ values plotted versus normalized current before (black) and after (red) machine improvements.

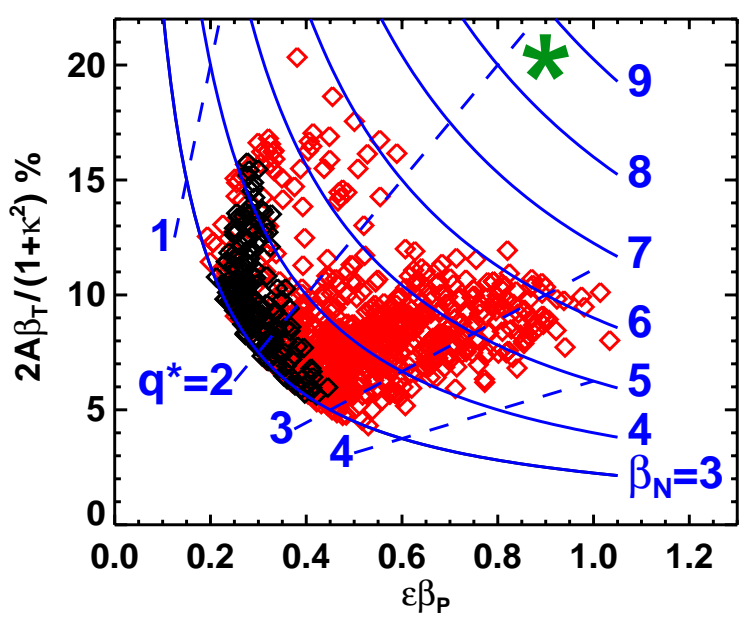

Figure 6. Peak re-scaled toroidal $\beta$ values plotted versus poloidal beta before (black) and after (red) machine improvements. Only discharges with $\beta_{N} \geq 3$ are plotted. The NSTX design target is indicated by the star symbol.

shows that $\langle\beta\rangle$ and $\left\langle\beta_{N}\right\rangle$ have more than doubled for $I_{p} / a B_{T 0} \leq 4$, but $\langle\beta\rangle$ exhibits saturation at higher normalized current.

A significant contributing factor to the large increase in $\left\langle\beta_{N}\right\rangle$ values at lower $I_{p} / a B_{T 0}$ is the ability to operate at much higher poloidal beta which decreases the plasma paramagnetism and has recently allowed some discharges to become slightly diamagnetic. Figure 6 plots toroidal $\beta$ values rescaled to remove leading geometric terms in the dimensionless form of Sykes-Troyon scaling [23, 24]. As seen in the figure, prior to error field reduction and bake-out, $\epsilon \beta_{P}$ was limited to approximately 0.45 . This limit was set primarily by confinement degrada- 


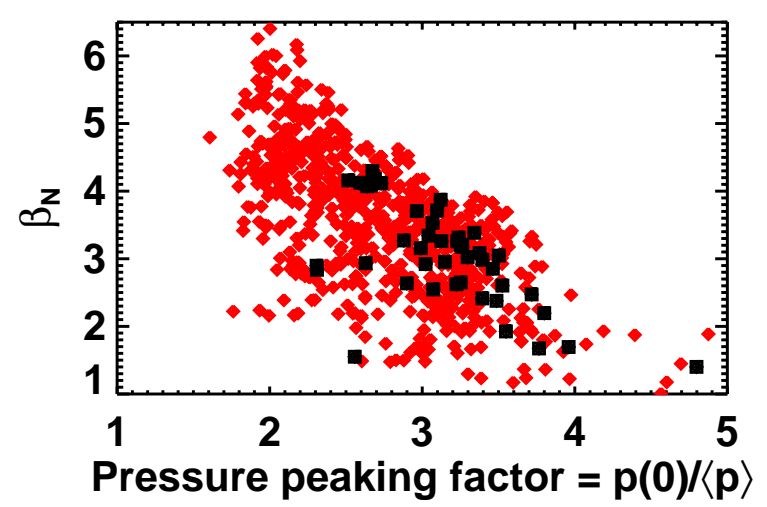

Figure 7. NSTX peak normalized $\beta$ values plotted versus pressure peaking factor before (black) and after (red) machine improvements.

tions associated with $2 / 1,3 / 2$, and $1 / 1$ tearing mode activity. These tearing modes had some of the characteristics of neoclassical tearing modes, but often did not seem to require a triggering or seeding event to initiate. Error field seeding and impurities likely contributed to this operational limit.

The NSTX design target [17] which utilizes wall stabilization to achieve $\beta_{N}=8.5$ and high $\epsilon \beta_{P} \approx$ 1 to achieve high bootstrap fraction is shown by the star symbol in Figure 6. As seen in the figure, $\epsilon \beta_{P}$ values in the desired range have now been achieved - but only at cylindrical safety factor $q^{*} \equiv$ $\epsilon\left(1+\kappa^{2}\right) \pi a B_{T 0} / \mu_{0} I_{p}$ values near 3 . To approach the NSTX design target, $\beta_{N}$ must increase by $35 \%$ at significantly lower $q^{*} \approx 2$. The design target also has a total pressure peaking factor in the range of 1.82 and a monotonic safety factor profile with $q \geq 2$ across the profile. The hollow current density profile consistent with the large off-axis bootstrap current density results in a very low internal inductance $l_{i} \approx$ 0.25 in the target configuration.

\subsection{Profile effects}

Consistent with theoretical expectations discussed above, Figure 7 shows a clear trend of increasing $\beta_{N}$ with decreasing pressure peaking factor $\equiv p(0) /\langle p\rangle$ in NSTX. In this figure, the pressure peaking is determined as a best fit to external poloidal magnetics and measured diamagnetic flux while using a scaled electron pressure profile as a loose fitting constraint [6] to guide the EFIT reconstructions. The pressure peaking factor reconstructed by the "partial-kinetic" EFIT in this fashion is typically $10-30 \%$ lower than that obtained kinetically from the sum of the measured ion and electron thermal pressure plus the fast
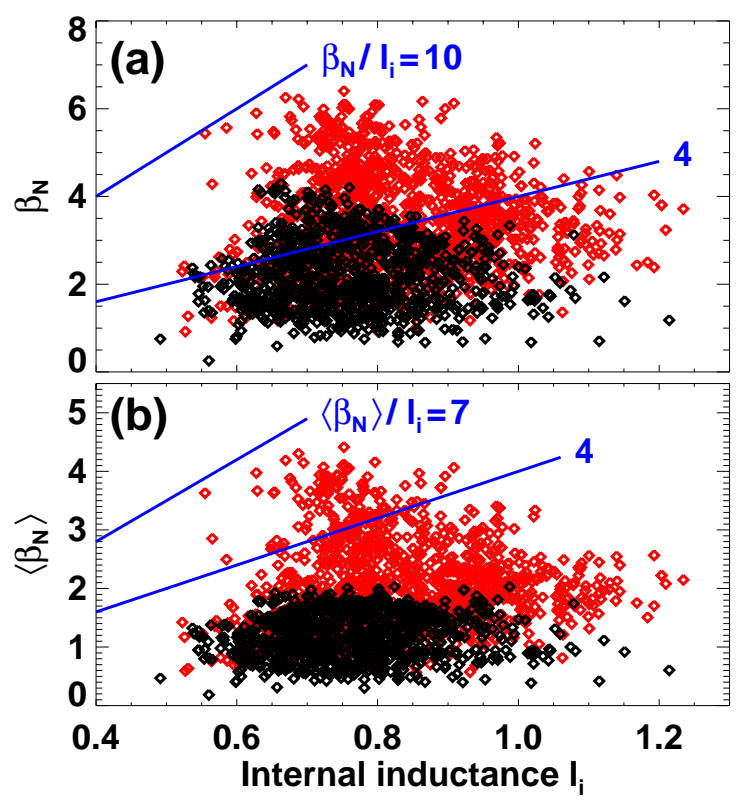

Figure 8. Peak normalized $\beta$ values plotted versus internal inductance before (black) and after (red) machine improvements. Lines indicate constant $\beta_{N} / l_{i}$ ratios.

ion pressure as computed by TRANSP [25]. These differences should have little impact on the trend shown in Figure 7, but do have implications for predicted stability limits as discussed in Section 4.3. below. However, the TRANSP calculation of the pressure peaking factor is likely an upper-bound, as any anomalous fast ion diffusion or loss will generally broaden the pressure profile.

An obvious issue in the present analysis is quantifying the importance of error field reduction relative to high temperature bakeout and H-mode access in increasing the $\beta$ limit in NSTX. Following error field reduction but prior to successful bakeout, L-mode discharge $\beta$-limit experiments were performed for a limited range of $I_{p} / a B_{T 0}$ near 6 . In these experiments, $\beta_{N}$ limits were observed to have increased from 4.1 to 4.8 for otherwise similar pressure peaking factor and internal inductance. From this data and from comparing $\beta_{N}$ limits before and after machine improvements at fixed pressure peaking (see Figure 7), we infer that static error field reduction alone increased the $\beta_{N}$ limit by $10-20 \%$. Additional increases in $\beta_{N}$ are therefore attributed to pressure profile broadening from $\mathrm{H}$-mode operation made possible by the high temperature bakeout.

Given the research goal of accessing very low $l_{i}$ regimes at high $\beta_{N}$, an important question in NSTX stability research is the beta limit scaling with internal inductance. Some higher aspect ratio experi- 


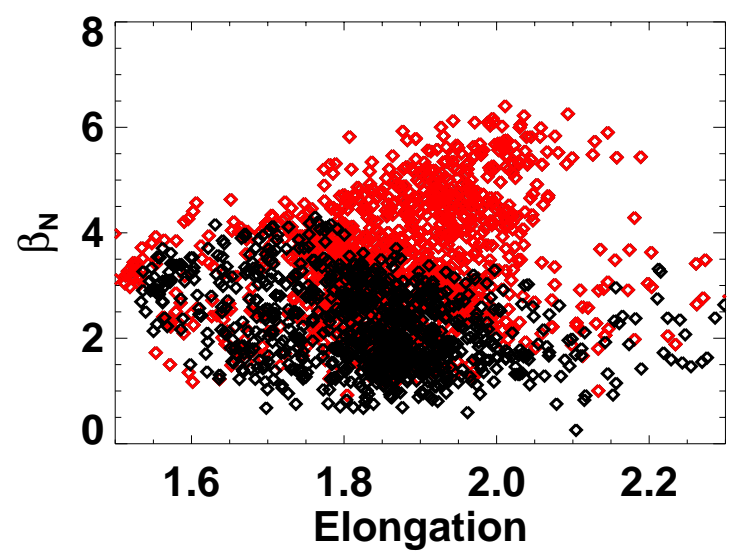

Figure 9. Peak $\beta_{N}$ values plotted versus boundary elongation before (black) and after (red) machine improvements.

ments have shown that the no-wall normalized beta limit obeys $\beta_{N} \leq 4 l_{i}[26]$. Figure 8a shows that this empirical limit has been exceeded by a factor of 2.5 at intermediate values of $l_{i} \approx 0.6$, and Figure $8 \mathrm{~b}$ shows that $\left\langle\beta_{N}\right\rangle$ also significantly exceeds $4 l_{i}$ by as much as a factor of 1.7. Perhaps more important than the high $\beta_{N} / l_{i}$ ratio is the trend of increasing $\beta_{N}$ with decreasing $l_{i}$ evident in the figures. Determining if this trend is upheld at lower $l_{i}$ is an important research topic, and future experiments will develop lower $l_{i}$ discharges to investigate beta limits at $l_{i}$ values approaching those of the NSTX design target.

\subsection{Influence of plasma shape}

Increased plasma shaping is well-known to improve tokamak ideal MHD stability, and NSTX is now able to routinely access significantly higher elongation and triangularity. As seen by the black symbols in Figure 9, there was previously little advantage to operating with elongation much above 1.8 in most discharges. Stability analysis for L-mode discharges obtained prior to machine improvements found that $n=1$ internal pressure-driven kink mode stability is degraded for elongation values above 1.8 when the pressure profile is sufficiently peaked - consistent with the data shown in Figure 9. For the data following machine improvements shown in red, the broader pressure profiles reduce the internal kink drive and excite a more global $\mathrm{n}=1$ mode which is more sensitive to boundary shaping and the influence of wall stabilization (see Section 4.3.). Such effects may explain why NSTX stability data now shows a trend of increasing $\beta_{N}$ with increasing elongation up to at least $\kappa=2.1$. The NSTX vertical control sys-

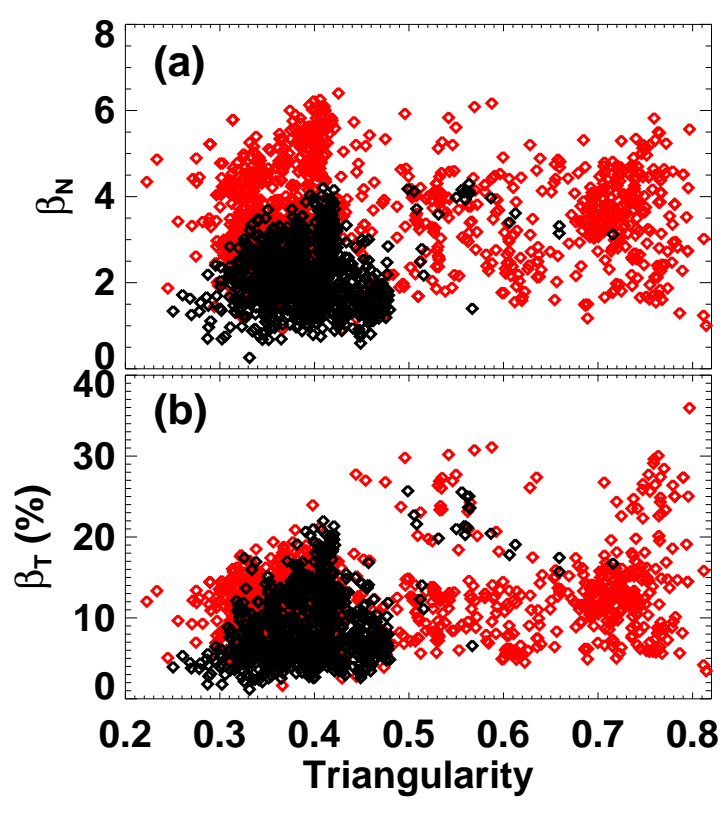

Figure 10. Peak (a) $\beta_{N}$ and (b) $\beta_{T}(\%)$ values plotted versus average triangularity before (black) and after (red) machine improvements.

tem is presently being upgraded to allow more routine access to even higher elongation to further test this trend.

As seen in Figure 10, NSTX also now more routinely operates at higher triangularity up to $\delta=$ 0.8 . Figure 10a shows that there is a relatively weak dependence of $\beta_{N}$ on triangularity for $\delta \geq 0.4$, but as seen in Figure 10b, the highest $\beta_{T}$ values have been achieved at the highest triangularities. Thus, the increase in $\beta_{T}$ is a result of the ability to operate at higher normalized current presumably due to the increased edge safety factor and shear at high $\delta$. Figure 10a also shows that $\beta_{N}$ values have increased for all triangularities - consistent with the finding that much of the improved stability in NSTX has come from decreased pressure profile peaking. Future experiments will focus more heavily on intermediate $\delta \approx 0.5-0.7$ and low $\delta \leq 0.3$ to more completely understand the dependence of the NSTX $\beta$ limit on triangularity.

\section{Beta-limiting MHD modes}

Pressure-driven kink-ballooning modes and resistive wall modes have been previously shown [6] to be beta-limiting in NBI-heated NSTX discharges. Neoclassical tearing modes have also recently been shown to be a concern [27] for any ST operating regime which relies upon high poloidal beta and 
bootstrap fraction. The following subsections discuss the modes typically observed to limit performance at the highest $\beta_{T}$ and $\beta_{P}$ values achieved following recent machine improvements.

\subsection{High $\beta_{T}$ discharges}

Figure 6 shows that the present operating limit of $\beta_{N} \approx 6$ restricts the accessible $\beta_{P}$ and bootstrap fraction for the highest $\beta_{T}$ discharges at low $q^{*} \leq$ 2 . Such discharges also often have low central safety factor near 1 at high $\beta$. The fast ion stored energy is typically $15-30 \%$ of the total in these discharges, and assuming classical slowing down, the fast ion pressure is often comparable to the thermal pressure near the magnetic axis. In such discharges, $n=1$ pressure-driven internal kink modes are computed to be ideally unstable with the approximation that the thermal plus fast ion pressure can be treated as isotropic since $\left(p_{\perp}-p_{\|}\right) / p_{\text {tot }}$ is computed to be less than $15 \%$ throughout the plasma. Experimentally, core $\mathrm{n}=1$ modes are observed to grow on 5 to $20 \mathrm{~ms}$ time-scales and often exhibit saturation followed by slow amplitude decay. These large internal $m / n=1 / 1$ modes can also lead to saturation in $\beta$, degradation in plasma rotation, and sometimes rapid disruption.

An example of such behavior for two 1MA discharges with $B_{T 0}=3 \mathrm{kG}$ which reach $\beta_{T}=25 \%$ and $31 \%$ is shown in Figure 11. As seen in Figure 11b, $\beta_{T}$ exhibits saturation from $\mathrm{t}=225 \mathrm{~ms}$ to $260 \mathrm{~ms}$ in both discharges despite the previous increase in NBI heating power by a factor of 3 . Most discharges in this parameter range never recover from the onset of this mode activity and exhibit beta limits of $\beta_{P} \approx 0.5$ and $\beta_{N} \approx 4-4.5$. As seen in the Figures $11 \mathrm{c}$ and $\mathrm{d}, 10-15 \mathrm{kHz} n=1$ modes become unstable near $\mathrm{t}=220 \mathrm{~ms}$ following $\mathrm{q}(0)$ approaching 1 near $\mathrm{t}=200 \mathrm{~ms}$. The highest $\beta_{T}$ discharge in Figure 11 is unique in that the limiting mode amplitude decreases after $\mathrm{t}=260 \mathrm{~ms}$ allowing the $\beta$ to increase and ultimately reach $\beta_{P} \approx 0.7$ and $\beta_{N} \approx 6.2$ prior to a undergoing an uncommonly rapid $400 \mathrm{MA} / \mathrm{s}$ plasma current disruption.

Insight into the structure of this $\beta$-limiting $1 / 1$ mode can be gained from correlating the plasma rotation profiles to fluctuation spectra from the NSTX ultra-soft X-ray (USXR) array [28]. Figure 12 shows that the chords with highest emission fluctuation amplitude correlate well in both frequency and minor radius with regions of flattened angular frequency measured using carbon charge exchange recombination spectroscopy [29]. This figure also
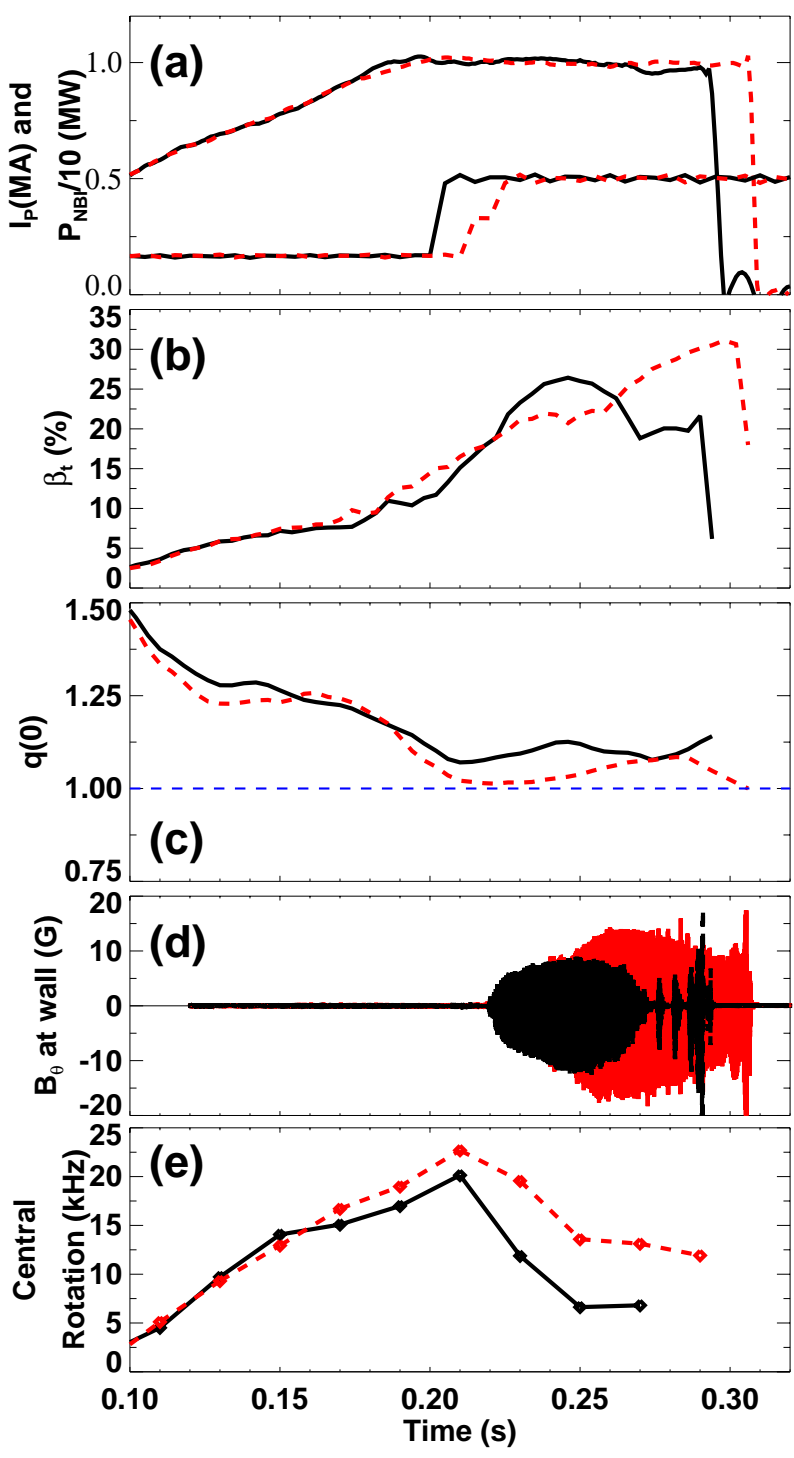

Figure 11. Time histories of $1 \mathrm{MA}$ high $\beta_{T}$ discharges 108101 (solid) and 108103 (dashed). Shown are (a) $I_{p}(\mathrm{MA})$ and $P_{N B I} / 10(\mathrm{MW})$, (b) toroidal beta, (c) q(0), (d) $10-15 \mathrm{kHz} \mathrm{n}=1$ mode amplitude at the midplane vacuum vessel wall, and (e) central rotation frequency from carbon impurity charge exchange.

indicates that the mode initiates in the core far from the $2 / 1$ surface but inside the $\mathrm{q}=1$ surface. Later in time at $\mathrm{t}=280 \mathrm{~ms}$, the mode radius has grown to $r / a=0.4-0.5$, and the localization of the rotation flattening likely indicates the presence of a large $1 / 1$ island. Near $\mathrm{t}=305 \mathrm{~ms}$, the mode grows further, slows, and then locks leading to discharge termination. The wide region of very weak shear and $q \approx 1$ evident in Figure 12 likely contributes to the rapidity of the discharge termination.

From the discussion above, it is evident that high- 


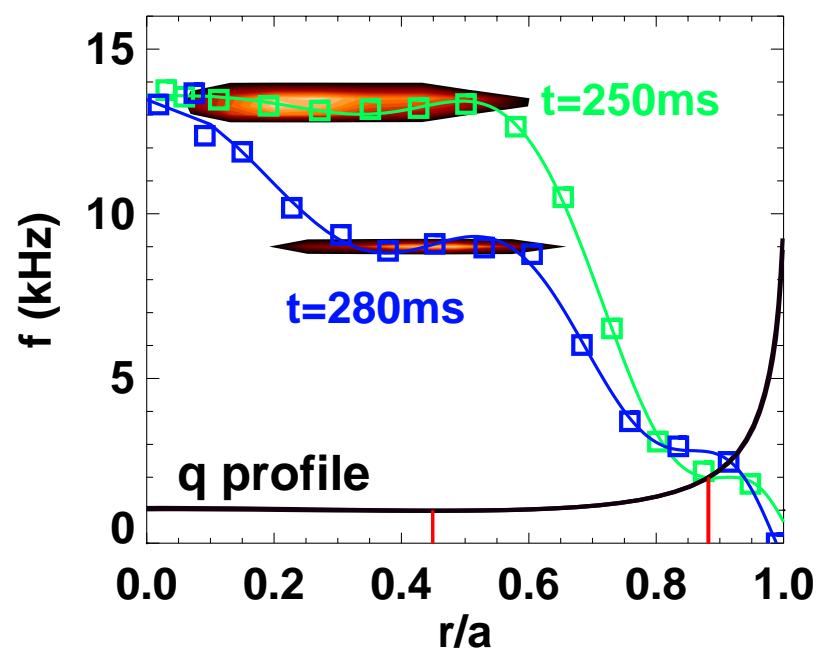

Figure 12. Carbon impurity rotation profiles (square symbols) and USXR frequency spectra (filled contours) versus minor radius at $\mathrm{t}=250$ and $280 \mathrm{~ms}$ for discharge 108103 shown in Figure 11.

est $\beta_{T}$ discharges in NSTX can clearly be limited in performance by tearing modes. However, the role of neoclassical drive in the mode growth is not yet clear, as many such discharges are near the beta limit for internal pressure driven kink modes. In particular, the classical tearing drive can be naturally strong due to positive tearing index $\Delta^{\prime}[30]$ computed near ideal limits. As seen in Figure 11, it is possible for the mode amplitude to decrease with increasing $\beta$ suggesting that neoclassical tearing drive may not be the dominant term determining mode growth. Finally, the discharges shown in Figure 11 are computed to have a total bootstrap fraction in the range of only $15-20 \%$ as computed by TRANSP - significantly lower than the highest values achieved in NSTX.

\subsection{High $\beta_{P}$ discharges}

In contrast to the lower $\beta_{P}$ achievable at high $\beta_{T}$, Figure 13 shows time-traces of a typical high $\beta_{P}$ discharge with $I_{p}=800 \mathrm{kA}, B_{T 0}=4.5 \mathrm{kG}$, and bootstrap current fraction of 35 to $40 \%$. Figure 13a shows that during the first $400 \mathrm{~ms}$ of this discharge, an $\mathrm{n}=2$ mode is measured to initiate near $300 \mathrm{~ms}$ coincident with a short burst of $n=1$ activity. At $t=430 \mathrm{~ms}$, Figure $13 \mathrm{c}$ shows that a another burst of $\mathrm{n}=1$ activity causes a drop in $\beta_{P}$ followed by a subsequent re-heat of the plasma. After this burst at $430 \mathrm{~ms}$, Figure $13 \mathrm{~d}$ shows that a longer-lived lower-frequency $n=1$ mode initiates. Figure 13e shows that each continuous mode and $n=1$ burst event decreases the central rotation

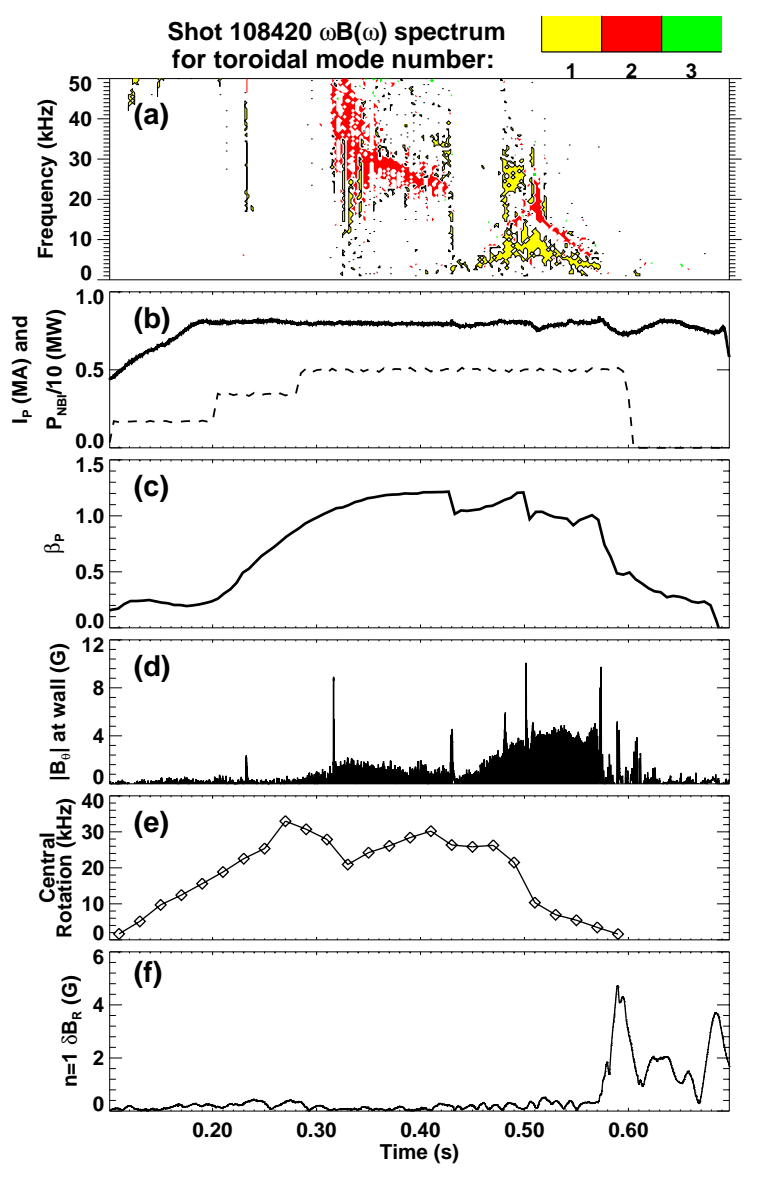

Figure 13. Time history for high $\beta_{P}$ discharge 108420. Shown are (a) Mirnov spectrogram indicating toroidal mode numbers of observed modes, (b) $I_{p}$ (solid) and $P_{N B I} / 10$ (dashed), (c) poloidal beta, (d) mode amplitude at the midplane vacuum vessel wall, (e) central rotation frequency from carbon impurity charge exchange, and (f) $\mathrm{n}=1$ locked-mode signal.

speed, and following the second collapse in $\beta_{P}$ at $\mathrm{t}=500 \mathrm{~ms}$, the rotation decay is accelerated. Finally, Figure 13f shows that after the plasma rotation is everywhere below approximately 2 to $4 \mathrm{kHz}$, the $\mathrm{n}=1$ locked-mode signal increases rapidly and leads to a rapid decay in $\beta_{P}$ prior to beam turn off at $\mathrm{t}=600 \mathrm{~ms}$.

Figure 14 correlates impurity rotation frequency to USXR mode activity for the discharge of Figure 13. As seen in the figure, at $\mathrm{t}=350 \mathrm{~ms}$ the central rotation frequency is $20-25 \mathrm{kHz}$ and no strong core MHD activity is evident in the USXR signals at this time. Only small modes at large minor radius are possibly impacting confinement near $\mathrm{r} / \mathrm{a}=0.7$ to 0.8 as suggested by the flattening of the local rotation profile there. However, following the second collapse in $\beta_{P}$ at $\mathrm{t}=500 \mathrm{~ms}$, the growth of the $7-10 \mathrm{kHz} \mathrm{n}=1$ 


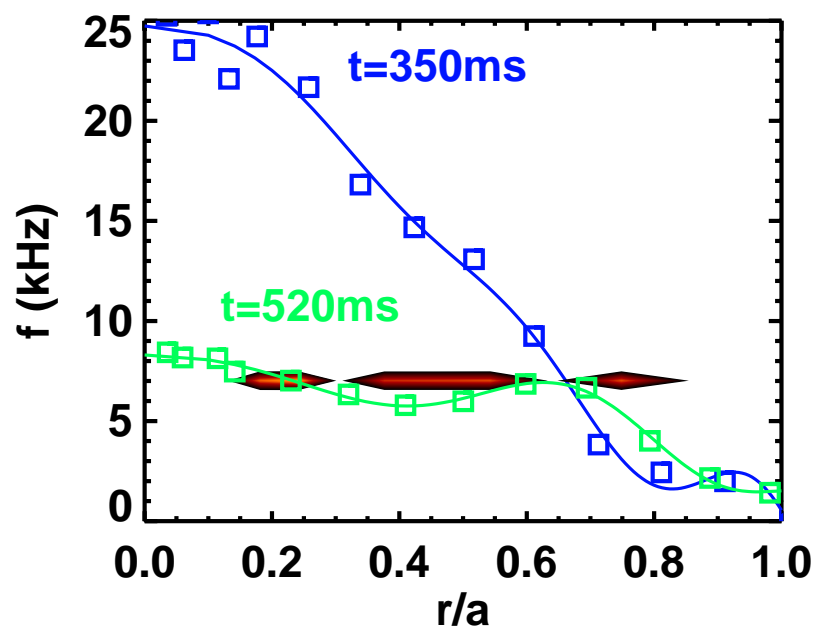

Figure 14. Carbon impurity rotation profiles and USXR frequency spectra versus minor radius at $\mathrm{t}=350 \mathrm{~ms}$ and $\mathrm{t}=520 \mathrm{~ms}$ for discharge 108420 shown in Figure 13.

mode appears to correlate well with the flattening of the core rotation at $t=520 \mathrm{~ms}$ and also the subsequent further decay of the plasma rotation. Thus, as for high $\beta_{T}$ discharges in NSTX, low-n mode induced confinement degradation and rotation decay appear to be important factors in the disruption dynamics of high $\beta_{P}$ discharges.

Prior to the onset of the abrupt drops in $\beta_{P}$ in Figure 13, the global energy confinement time for this $6 \mathrm{MW}$ discharge is $40-50 \mathrm{~ms}$ with $\mathrm{H}$-factor of 2 2.5 relative to ITER-89P scaling [31]. This confinement estimate ignores the 1 to $2 \mathrm{MW}$ loss of NBI heating power to prompt loss and charge exchange due to operating at reduced plasma current and low internal inductance. Thus, if there is a stronger neoclassical drive for the tearing modes in these higher $\beta_{P}$ discharges, the overall confinement is clearly not degraded to the point where high $\beta_{P}$ is inaccessible. However, if $\mathrm{n}=1$ internal disruptions do occur in the high $\beta_{P}$ phase, it is rare for the stored energy to fully recover, and the low-n modes shown in Figure 13a after $\mathrm{t}=430 \mathrm{~ms}$ may be neoclassical tearing modes. In addition, given the lower toroidal field 1MA results discussed previously, the presence of these modes would likely further degrade confinement at lower $q^{*}$ unless methods are developed to retain the apparently favorable elevated q profile in the high $\beta_{P}$ discharges. Future work modeling the growth of these tearing modes will require an accurate treatment of the nearby conducting structure, as these modes are classically unstable without a nearby wall due to the

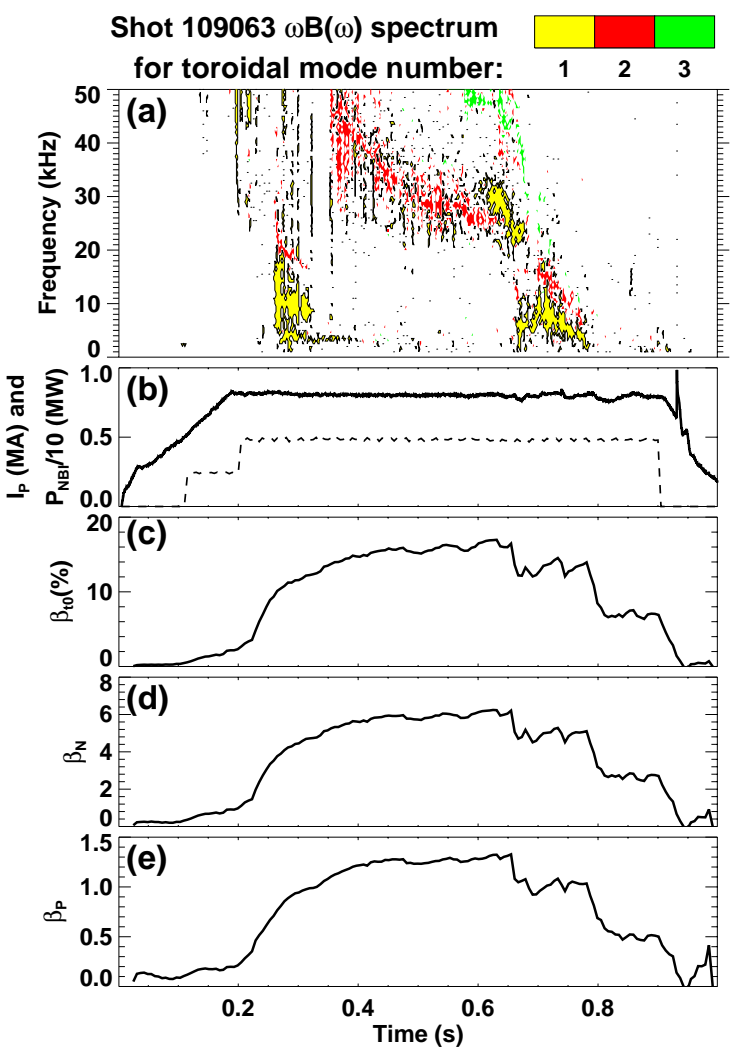

Figure 15. Time history for long-pulse discharge 109063. Shown are (a) Mirnov spectrogram indicating toroidal mode numbers of observed modes, (b) $I_{p}$ (solid) and $P_{N B I}$ (dashed), (c) toroidal beta, (d) normalized beta, and (e) poloidal beta.

strong ideal drive from operating above the no-wall limit.

Finally, by reducing the NBI heating power and further raising the toroidal field, it is possible to significantly delay the deleterious MHD activity evident in Figure 13. Figure 15 shows the history of the longest duration discharge obtained in NSTX at $I_{p}=800 \mathrm{kA}$ and $B_{T 0}=5 \mathrm{kG}$. As seen in the figure, only a long-lived $\mathrm{n}=2$ mode is observable in the Mirnov spectrogram from $\mathrm{t}=350$ to $650 \mathrm{~ms}$. As in Figure 13, once the $\mathrm{n}=1$ mode initiates near $\mathrm{t}=650 \mathrm{~ms}$, partial collapses of $\beta_{N}$ are observed and the discharge stored energy never fully recovers. Rotation data is unavailable for this discharge, but it is likely that the rotation decay evolution is similar to that shown in Figure 13. Prior to the onset of the $n=1$ activity at $\mathrm{t}=650 \mathrm{~ms}$, Figures $15 \mathrm{c}$-e show that $\beta$ values of $\beta_{T}=16 \%, \beta_{N}=6$, and $\beta_{P}=1.3$ are obtained in quasi-steady-state for $250 \mathrm{~ms}$. This time interval corresponds to approximately one current relaxation time in NSTX. Clearly, understanding the origin of 
the disruptive $\mathrm{n}=1$ mode at high $\beta_{P}$ and $\beta_{N}$ will be essential to further lengthening NSTX discharges.

\subsection{Ideal kink stability limits at high $\beta_{P}$}

NSTX was specifically designed with a closefitting segmented copper shell to provide wall stabilization of the external kink mode to achieve $\beta$ values significantly above the no-wall limit. NSTX presently has only unidirectional neutral beam injection (NBI), and the plasma routinely spins with a central rotation frequency in the range of $15-35 \mathrm{kHz}$ in the same direction as the plasma current. The central thermal rotation speed normalized to the local Alfven speed can exceed 0.2 in NSTX, so rotational stabilization of the resistive wall mode $[6,32]$ is expected to impact the stability limits of many NSTX discharges. To clarify the role of wall stabilization, it is desirable to determine the proximity of a discharge to both the no-wall and with-wall limits. On NSTX, this can be rapidly done using the "partial-kinetic" EFIT reconstructions [6] between shots and the DCON ideal stability code [33]. Recently, calibrated ion temperature data has become available for some of the highest $\beta$ and $\beta_{N}$ discharges, and this has allowed initial TRANSP calculations of the total pressure profile. NSTX does not yet have internal magnetic field measurements, so a significant source of uncertainty in the stability calculations is the q profile. However, the fitting model in EFIT for NSTX very often reproduces the measured inversion radii of sawteeth and locations of $1 / 1$ and $2 / 1$ tearing modes. Given this success and the fact that the $n=1$ global kink mode is relatively insensitive to fine details of the (monotonic) q profile, the q profile from the partial-kinetic EFIT reconstructions is used in the stability analysis that follows.

One of the key results of Reference [22] is the finding that the no-wall stability limit set by ballooning and low-n kink modes is $\left\langle\beta_{N}\right\rangle \approx 3.1 \pm 0.3$ for cylindrical kink safety factor $q^{*} \geq 1.7$. The computed limit was found to hold for shaped tokamak plasmas over a wide range of aspect ratios. As seen in Figure 5, many discharges with $I_{p} / a B_{T 0}$ in the range of 2.5-3.5 have apparently violated this limit by a significant fraction and are good candidates for preliminary stability analysis. Figure 16 plots the time dependence of several parameters of an $I_{p}=800 \mathrm{kA}$, $B_{T 0}=5 \mathrm{kG}$, lower single null $\mathrm{H}$-mode discharge which uses $P_{N B I}=6 \mathrm{MW}$ to reach $\beta_{T}=17 \%$ and $\beta_{P}=1.4$ but is otherwise identical to the discharge shown in Figure 15. As seen in Figures 16a-c, q(0) and $l_{i}$ reach
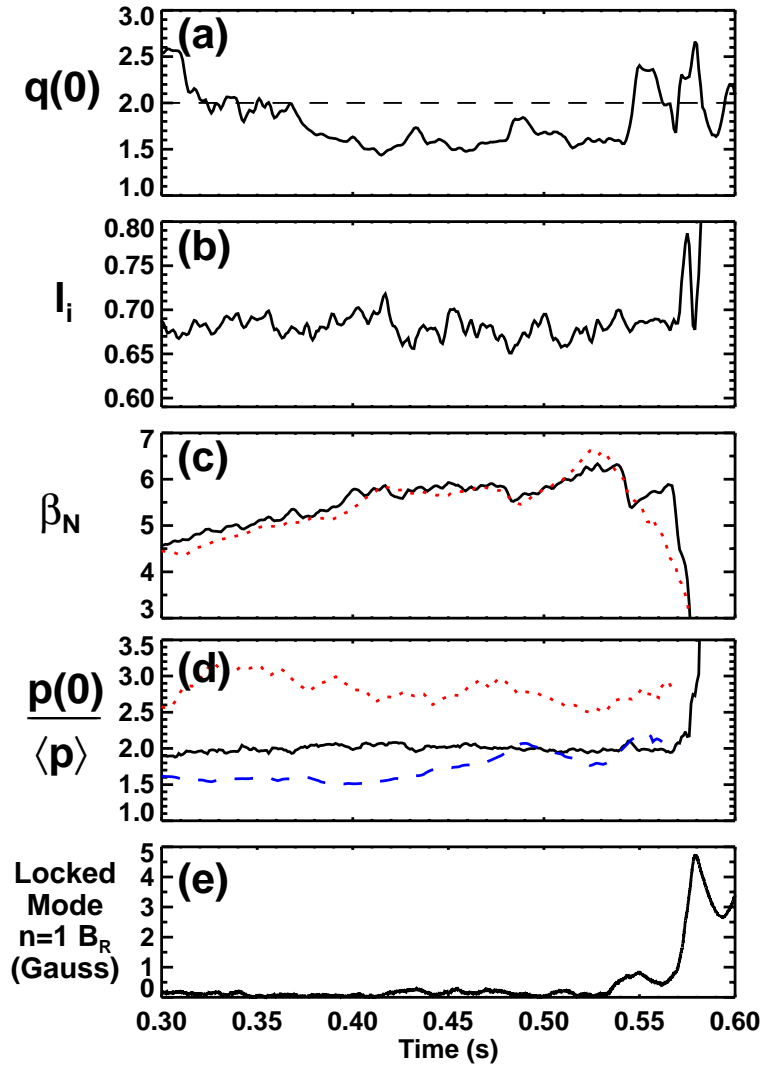

Figure 16. Time traces of (a) central safety factor, (b) internal inductance, (c) normalized beta, (d) pressure peaking factor, and (e) locked mode signal for high $\beta_{N}$ shot 109070 . Solid lines indicate results from partial kinetic EFIT and dotted lines correspond to TRANSP results. Dashed line in (d) corresponds to thermal pressure peaking.

quasi-steady values, while the normalized $\beta$ increases slowly in the $200 \mathrm{~ms}$ prior to the partial collapses and eventual disruption in plasma stored energy. Figure 16d shows that the total pressure peaking factors from EFIT (solid line) and TRANSP (dotted line) also reach nearly constant values. However, this discharge does not achieve density flat-top, and the fraction of stored energy in the fast ion component is decreasing as a function of time. The thermal pressure profile (shown by the dashed line in Figure 16d) is found to increase in peaking factor as the $\mathrm{H}$-mode density profile transitions from hollow to monotonic. Thus, the total pressure profile shape is changing in this discharge while keeping the peaking factor nearly constant. Finally, Figure 16e shows that there is a small 0.5 Gauss precursor $30 \mathrm{~ms}$ prior to the final collapse of the discharge. Details of resistive wall mode signatures, toroidal flow damping, and critical rotation threshold physics in these and similar col- 


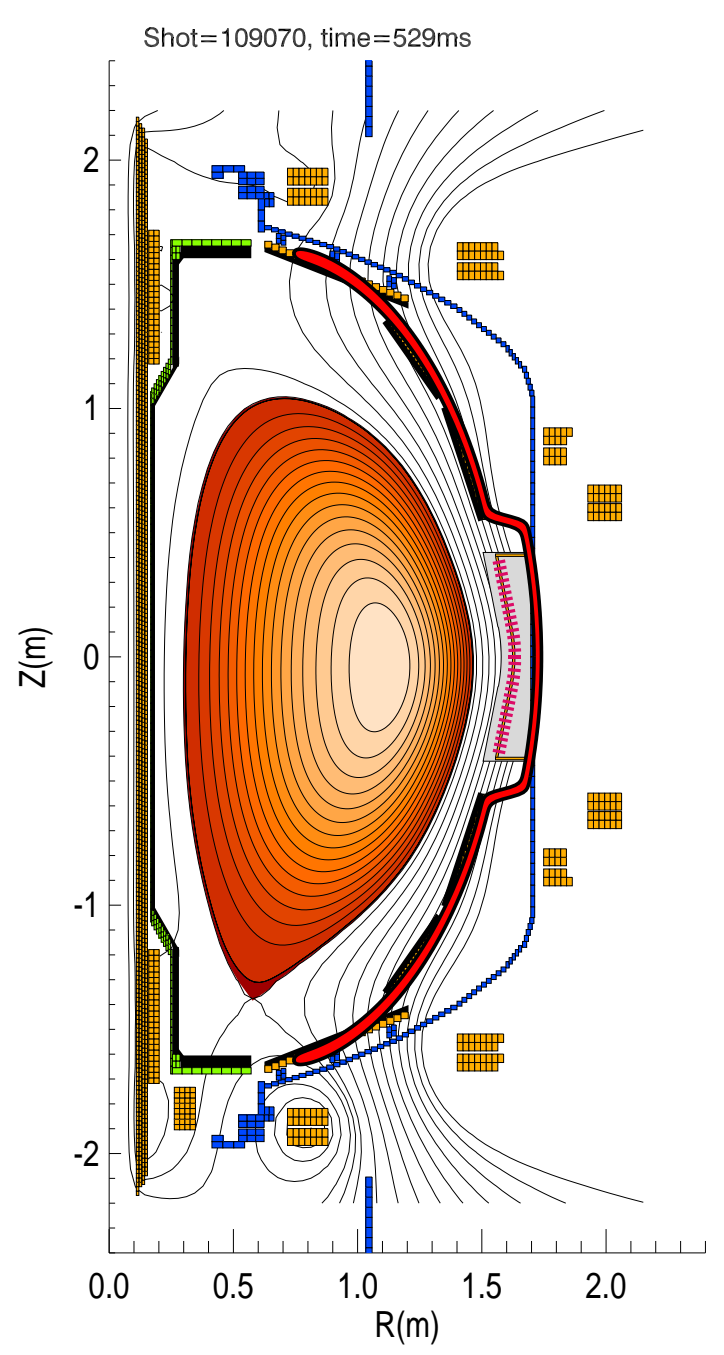

Figure 17. Cross sectional view of NSTX coils, vessel, passive conducting plates, and lower single null plasma shape for the discharge shown in Figure 16. The solid closed curve on the outboard side indicates the conducting wall shape used in the stability calculations.

lapses are discussed in more detail in Reference [32].

An important element in achieving the high $\beta_{N}$ state shown in Figure 16 is avoidance of sawteeth and large edge localized modes (ELMs). The intermediate triangularity $\left(\delta_{u}=0.3, \delta_{l}=0.5\right)$ lower single null discharge shape with $\kappa=2.1$ shown in Figure 17 was found to produce $\mathrm{H}$-modes with small and infrequent ELMs. The discharge shape for maximizing global stability while retaining favorable ELM characteristics has not yet been fully optimized, as the impact of shaping on ELM stability [34] is just beginning to be studied in NSTX. Figure 17 also shows the outboard conducting shell model (solid closed curve)

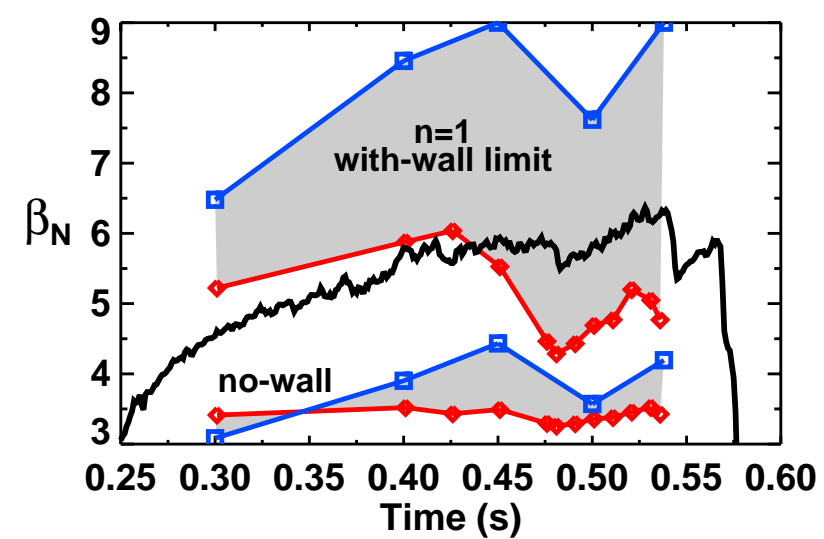

Figure 18. $n=1$ kink mode no-wall (lower shaded region) and with-wall (upper shaped region) marginally stable $\beta_{N}$ for the discharge of Figure 16 using the conducting wall model of Figure 17. The middle trace is the experimental $\beta_{N}$, square symbols correspond to marginal $\beta_{N}$ values for the EFIT pressure profile, diamonds to the TRANSP pressure profile.

used in stability calculations to model the effect of the copper passive conducting plates and stainlesssteel vessel wall.

Figure 18 shows the computed no-wall and withwall $\beta_{N}$ limits as a function of time preceding the collapse in stored energy for both the EFIT and TRANSP pressure profiles for shot 109070. In the marginal stability calculations, the EFIT and TRANSP equilibrium solutions are refined with the J-SOLVER [35] flux coordinate equilibrium solver, and the pressure profile shape and flux-surfaceaverage parallel current density profile shape are held fixed as $\beta$ is varied. The equilibrium boundary is chosen to be at the surface where $99-99.5 \%$ of the poloidal flux is enclosed such that the edge safety factor value is just above an integer value to eliminate the possible excitation of surface kink modes which are not of interest in the present analysis. As seen in the figure, the discharge is computed to exceed the computed no-wall limit of $\beta_{N}=3$ to 4 independent of which pressure profile is assumed. However, the predicted with-wall limit is found to be more sensitive to variations in the pressure profile peaking, and the experimental $\beta_{N}$ value is found to cross the withwall stability limit near $\mathrm{t}=450 \mathrm{~ms}$ using the TRANSP pressure profile, but to not reach this limit if the broader EFIT profile is used. However, both limits exhibit a decrease in the marginal $\beta_{N}$ after $\mathrm{t}=425 \mathrm{~ms}$, so a decreasing with-wall $\beta$ limit due to an evolv- 
ing pressure (and possibly current) profile combined with a slowly increasing $\beta$ may together explain the disruptions near the end of the discharge.

As seen in Figure 18, the experimental $\beta_{N}$ does exhibit a small but rapid decrease at $\mathrm{t}=480 \mathrm{~ms}$ followed by a subsequent rise and second crash much like that shown in Figure 15 above. After the onset of these MHD events, TRANSP calculations are found to overpredict the neutron rate implying that some fast ion loss or redistribution is occurring. Thus, TRANSP results may also be overpredicting the pressure peaking factor during the phase when the plasma is computed to be above the with-wall limit using the TRANSP pressure profile in Figure 18. Additional uncertainty in the peaking arises from the significant contribution of the centrally peaked rotational centrifugal force to the total pressure as discussed in Section 5. below. There are also many uncertainties in performing with-wall stability calculations with an idealized wall, such as the impact of cuts in the copper passive conducting structure and ports in the vessel wall which may increase the effective distance between the plasma and conducting wall. Such effects are more readily treated with 3D eddy current models already developed for NSTX using the VALEN code $[36,6,32]$.

Given the stability results shown in 18 , it appears very likely that discharges like that shown in Figure 16 are routinely operating above the no-wall $\beta$ limit. Reaching the with-wall $\beta$ limit appears to be a plausible explanation of the rapid and partial $n=1$ disruptions shown in Figures 13, 15, and 16, but this claim is sensitive to details of the pressure and current profiles and the conducting wall model used.

\section{Effects of rapid rotation}

The high rotation speed of many NSTX discharges not only impacts $\beta$ limits through wall stabilization, but can also modify the underlying equilibrium itself. As mentioned previously, thermal ion rotation speeds as high as 0.2 times the local Alfven speed are not uncommon in the core of NSTX plasmas, and in diamagnetic discharges the thermal rotational Alfven Mach number $M_{A} \equiv v_{\phi} / v_{A}$ can be as high as 0.3 . The centrifugal force of the spinning plasma most strongly modifies force balance near the magnetic axis where the pressure gradient would otherwise be small. Assuming the thermal temperatures are poloidal flux functions, the shift of peak pressure outward from the magnetic axis should imply an even larger increase in the major

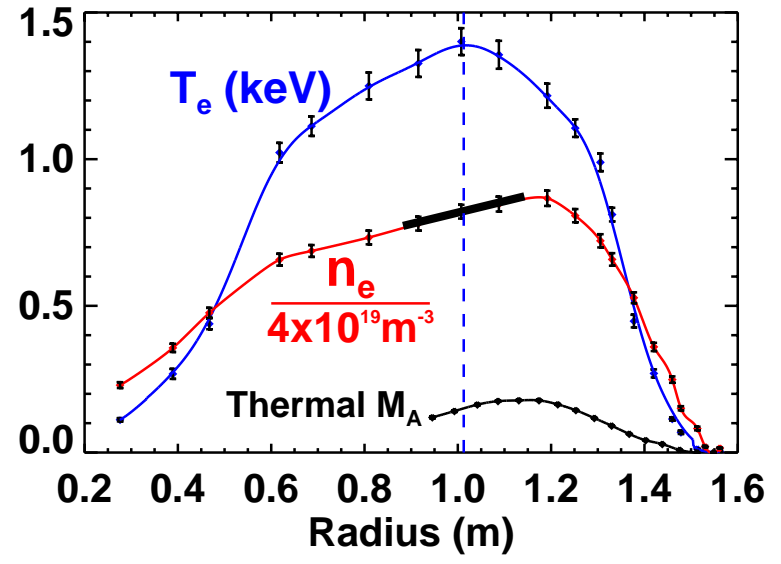

Figure 19. Profiles of electron temperature (upper curve), electron density (middle curve), and thermal plasma rotational Alfven Mach number (lower curve) plotted versus major radius for shot 107540 at $\mathrm{t}=318 \mathrm{~ms}$.

radius of maximum density and finite density gradient at the magnetic axis. This shift in density is indeed observable as seen in Figure 19 which plots profiles of electron temperature, electron density, and thermal $M_{A}$ for an MHD-quiescent L-mode discharge heated with $1.7 \mathrm{MW}$ of $80 \mathrm{keV}$ neutral beams. For this discharge, the central rotation frequency reaches $30 \mathrm{kHz}$ and the thermal $M_{A}$ at the magnetic axis (indicated by the vertical dashed line) reaches 0.15 . At the axis, radial force balance dictates that $R d\left[\log \left(n_{e}\right)\right] / d R=2 M_{A}^{2} / \beta_{\text {total }}$. In this expression, $M_{A}$ includes both the thermal ion rotation and the angular velocity of the beam-generated fast ion population which has a mean angular frequency 4 to 5 times higher than the thermal plasma bulk. The total pressure is again taken to be isotropic, and for this relatively low density discharge, approximately $2 / 3$ of the outward centrifugal force near the axis comes from the fast ion component. The solid line overlaying the density profile in the figure represents the gradient expected from force balance arguments and is in good agreement with the measured core gradient when the fast ion centrifugal force is included. The core electron density asymmetry in NSTX discharges is often weaker than that shown in Figure 19, as effects such as core MHD activity can reduce the core thermal and fast ion rotation and centrifugal force.

Finally, in addition to strong flow modifying equilibria, flow shear may also impact MHD stability. Initial calculations using the M3D code for NSTX [37] find that for self-consistent MHD equilibria with 
flow included, linear growth rates of $n=1$ internal pressure-driven kink modes with $\mathrm{q}(0)<1$ can be reduced by as much as a factor of 3 due to flow shear. Fast particle effects, two-fluid effects, and having $q(0)>1$ are all further stabilizing, and non-linearly saturated states with $\beta$ values significantly above ideal-marginal values may be possible. Determining if such effects are contributing to the achievement of very high $\beta$ values for plasmas like that shown in Figure 11 is a topic for future research.

\section{Summary}

Device and operational improvements have led to a significant increase in global magnetohydrodynamic stability limits in NSTX plasmas. Pressure profile broadening from $\mathrm{H}$-mode operation combined with reduced error fields now allow access to normalized beta values as high as $\beta_{N}=6.4$ and $\left\langle\beta_{N}\right\rangle=$ 4.5. Maximum toroidal beta values have reached $\beta_{T}$ $=35 \%$ and volume-average beta values $\langle\beta\rangle=15 \%$. High poloidal beta operation with $\beta_{P} \leq 1.4$ has allowed a doubling of discharge pulse-length to just over 1 second with sustained periods of $\beta_{N} \approx 6$. High $\beta_{N}$ values have been achieved at low internal inductance with $\beta_{N} / l_{i} \leq 10$. Stability analysis indicates that many of the high $\beta_{P}$ discharges at high $\beta_{N}$ are routinely operating above the nowall stability limit and may be disrupting at least in part due to proximity to the with-wall limit. Central rotation damping is often observed to precede the final thermal disruption phase in these discharges and may be contributing to the destabilization of resistive wall modes. Long-lived $2 / 1$ or $3 / 1$ tearing modes are also observed at large minor radius in these discharges, and these modes appear to impact edge confinement without significantly degrading the overall discharge. At higher $\beta_{T}$ and lower q, core $1 / 1$ modes are found to most often saturate $\beta_{T}$ and $\beta_{P}$, although very rapid current and thermal disruptions are sometimes observed. Rapid rotation from unidirectional beam injection is observed to modify radial force balance such that pressure and density are no longer flux functions. In addition, large rotational shear has been theoretically shown to help suppress internal kink modes and may contribute to the saturation of $1 / 1$ modes in the highest $\beta_{T}$ discharges of NSTX.

\section{Acknowledgments}

This work was supported by the United States Department of Energy under contract numbers DE-AC02-76CH03073 (PPPL), DE-AC05-00R22725 (ORNL), W-7405-ENG-36 (LANL) and grant numbers DE-FG02-99ER54524 (CU), DE-FG0299ER54523 (JHU).

\section{References}

[1] PENG, Y.-K. M. and STRICKLER, D. J., Nucl. Fus. 26 (1986) 769.

[2] STAMBAUGH, R. D., CHAN, V. S., MILLER, R. L., and SCHAFFER, M. J., Fus. Technol. 33 (1998) 1 .

[3] JARDIN, S. C., KESSEL, C. E., MENARD, J., MAU, T. K., NAJMABADI, F., et al., Fus. Engin. and Design 65 (2003) 165.

[4] ONO, M., KAYE, S., PENG, Y.-K., BARNES, G., BLANCHARD, W., et al., Nucl. Fus. 40 (2000) 557.

[5] KAYE, S., ONO, M., PENG, Y.-K., BATCHELOR, D., CARTER, M., et al., Fus. Technol. 36 (1999) 16.

[6] SABBAGH, S. A., BELL, R. E., BELL, M. G., BIAlEK, J., GLASSER, A. H., et al., Phys. Plasmas 9 (2002) 2085.

[7] SKInNER, C. H., KUGEL, H. W., MAINGI, R., WAMPLER, W. R., BLANCHARD, W., et al., Nucl. Fus. 42 (2002) 329.

[8] KUGEL, H. W., SOUKHANOVSKII, V., BELL, M., BLANCHARD, W., GATES, D., et al., J. Nucl. Mater. (2003), "Impact of the wall conditioning program on plasma performance in NSTX", in press.

[9] MAINGI, R., BELL, M., BELL, R., BUSH, C., FREDRICKSON, E., et al., H-mode research in NSTX, in Proceedings of the 19th IAEA Fusion Energy Conference, International Atomic Energy Agency, 2002, Paper EX/C2-5.

[10] LAHAYE, R. J., FITZPATRICK, R., HENDER, T. C., MORRIS, A. W., SCOVILLE, J. T., et al., Phys. Fluids B 4 (1992) 2098.

[11] HENDER, T. C., FITZPATRICK, R., MORRIS, A. W., CAROLAN, P. G., DURST, R. D., et al., Nucl. Fus. 32 (1992) 2091.

[12] BUTTERY, R. J., DE'BEnEDETTI, M., HENDER, T. C., and TUBBING, B. J. D., Nucl. Fus. 40 (2000) 807.

[13] LAZZARO, E., BUtTERY, R. J., HENDER, T. C., ZANCA, P., FITZPATRICK, R., et al., Phys. Plasmas 9 (2002) 3906.

[14] GAROFALO, A. M., JENSEN, T. H., JOHNSON, L. C., HAYE, R. J. L., NAVRATIL, G. A., et al., Phys. Plasmas 9 (2002) 1997.

[15] FITZPATRICK, R., Nucl. Fus. 33 (1993) 1049. 
[16] WHITE, R. B., Theory of Tokamak Plasmas, North-Holland Publishing Company, Amsterdam, 1989.

[17] MENARD, J. E., JARDIN, S. C., KAYE, S. M., KESSEL, C. E., and MANICKAM, J., Nucl. Fus. 37 (1997) 595.

[18] PAOLETTI, F., SABBAGH, S., MANICKAM, J., MENARD, J., AKERS, R., et al., Nucl. Fus. 42 (2002) 418.

[19] MAINGI, R., BELL, M. G., BELL, R. E., BUSH, C. E., FREDRICKSON2, E. D., et al., Phys. Rev. Lett. 88 (2002) 035003.

[20] LAO, L. L., St. John, H., STAMBAUGH, R. D., KELLMAN, A. G., and PFEIFFER, W., Nucl. Fus. 25 (1985) 1611.

[21] SABBAGH, S. A., KAYE, S. M., MENARD, J., BELL, M., BELL, R., et al., Nucl. Fus. 41 (2001) 1601.

[22] MENARD, J., BELL, M., BELL, R., GATES, D., KAYE, S., et al., Unified ideal stability limits for advanced tokamak and spherical torus plasmas, to be submitted to Phys. Plasmas.

[23] SYKES, A., TURNER, M., and PATEL, S., Beta limits in tokamaks due to high-n ballooning modes, in METHFESSEL, S., editor, Proceedings of the 11th European Conference on Controlled Fusion and Plasma Physics, Aachen, Germany, 1983, volume 7D, Part II, p. 363, Switzerland, 1983, European Physical Society, Petit-Lancy.

[24] TROYON, F., GRUBER, R., SAURENMANN, H., SEMENZATO, S., and SUCCI, S., Plasma Phys. and Contr. Fus. 26 (1984) 209.

[25] GOLdstOn, R. J., MCCUNE, D. C., and TOWNER, H. H., J. Comput. Phys. 43 (1981) 61.

[26] STRAIT, E., Phys. Plasmas 1 (1994) 1415.

[27] BUTTERY, R. J., SAUTER, O., AKERS, R., GRYAZNEVICH, M., MARTIN, R., et al., Phys. Rev. Lett. 88 (2002) 125005.

[28] STUTMAN, D., FINKENTHAL, M., SOUKHANOVSKII, V., MAY, M., MOOS, H., et al., Rev. Sci. Instrum. 70 (1999) 572.

[29] BELL, R., LEBLANC, B., BOURDELLE, C., ERNST, D., FREDRICKSON, E., et al., Kinetic profiles in NSTX plasmas, Technical Report 3591, PPPL, 2001.

[30] BRENNAN, D. P., STRAIT, E. J., TURNBULL, A. D., CHU, M. S., HAYE, R. J. L., et al., Phys. Plasmas 9 (2002) 2998.

[31] LEBLANC, B., BELL, M., BELL, R., BOUDELLE, C., GATES, D., et al., Confinement studies of auxiliary heated NSTX plasmas, in Proceedings of the 19th IAEA Fusion Energy Conference, International Atomic Energy Agency, 2002, Paper EX/C5-2.

[32] SABBAGH, S., BELL, M., BELL, R., BUSH, C., FREDRICKSON, E., et al., The resistive wall mode and feedback control physics design in NSTX, in
Proceedings of the 19th IAEA Fusion Energy Conference, International Atomic Energy Agency, 2002, Paper EX/S2-2.

[33] GLASSER, A. and CHANCE, M., Bull. Am. Phys. Soc. 42 (1997) 1848.

[34] FERRON, J. R., CHU, M. S., JACKSON, G. L., LAO, L. L., MILLER, R. L., et al., Phys. Plasmas 7 (2000) 1976.

[35] DELUCIA, J., JARDIN, S. C., and TODD, A. M. M., J. Comput. Phys. 37 (1980) 183.

[36] BIALEK, J., BOOZER, A. H., MAUEL, M. E., and NAVRATIL, G. A., Phys. Plasmas 8 (2001) 2170.

[37] PARK, W., BRESLAU, J., CHEN, J., FU, G., JARDIN, S., et al., Nonlinear simulation studies of tokamaks and STs, in Proceedings of the 19th IAEA Fusion Energy Conference, International Atomic Energy Agency, 2002, Paper TH/5-1. 


\section{External Distribution}

Plasma Research Laboratory, Australian National University, Australia

Professor I.R. Jones, Flinders University, Australia

Professor João Canalle, Instituto de Fisica DEQ/IF - UERJ, Brazil

Mr. Gerson O. Ludwig, Instituto Nacional de Pesquisas, Brazil

Dr. P.H. Sakanaka, Instituto Fisica, Brazil

The Librarian, Culham Laboratory, England

Mrs. S.A. Hutchinson, JET Library, England

Professor M.N. Bussac, Ecole Polytechnique, France

Librarian, Max-Planck-Institut für Plasmaphysik, Germany

Jolan Moldvai, Reports Library, MTA KFKI-ATKI, Hungary

Dr. P. Kaw, Institute for Plasma Research, India

Ms. P.J. Pathak, Librarian, Insitute for Plasma Research, India

Ms. Clelia De Palo, Associazione EURATOM-ENEA, Italy

Dr. G. Grosso, Instituto di Fisica del Plasma, Italy

Librarian, Naka Fusion Research Establishment, JAERI, Japan

Library, Plasma Physics Laboratory, Kyoto University, Japan

Research Information Center, National Institute for Fusion Science, Japan

Dr. O. Mitarai, Kyushu Tokai University, Japan

Dr. Jiangang Li, Institute of Plasma Physics, Chinese Academy of Sciences, People's Republic of China

Professor Yuping Huo, School of Physical Science and Technology, People's Republic of China

Library, Academia Sinica, Institute of Plasma Physics, People's Republic of China

Librarian, Institute of Physics, Chinese Academy of Sciences, People's Republic of China

Dr. S. Mirnov, TRINITI, Troitsk, Russian Federation, Russia

Dr. V.S. Strelkov, Kurchatov Institute, Russian Federation, Russia

Professor Peter Lukac, Katedra Fyziky Plazmy MFF UK, Mlynska dolina F-2, Komenskeho Univerzita, SK-842 15 Bratislava, Slovakia

Dr. G.S. Lee, Korea Basic Science Institute, South Korea

Institute for Plasma Research, University of Maryland, USA

Librarian, Fusion Energy Division, Oak Ridge National Laboratory, USA

Librarian, Institute of Fusion Studies, University of Texas, USA

Librarian, Magnetic Fusion Program, Lawrence Livermore National Laboratory, USA

Library, General Atomics, USA

Plasma Physics Group, Fusion Energy Research Program, University of California at San Diego, USA

Plasma Physics Library, Columbia University, USA

Alkesh Punjabi, Center for Fusion Research and Training, Hampton University, USA

Dr. W.M. Stacey, Fusion Research Center, Georgia Institute of Technology, USA

Dr. John Willis, U.S. Department of Energy, Office of Fusion Energy Sciences, USA

Mr. Paul H. Wright, Indianapolis, Indiana, USA 
The Princeton Plasma Physics Laboratory is operated by Princeton University under contract with the U.S. Department of Energy.

\author{
Information Services \\ Princeton Plasma Physics Laboratory \\ P.O. Box 451 \\ Princeton, NJ 08543
}

Phone: 609-243-2750

Fax: 609-243-2751

e-mail: pppl_info@pppl.gov

Internet Address: http://www.pppl.gov 